\title{
Student Ability Best Predicts Final Grade in a College Algebra Course
}

\author{
Kyle A. O’Connell' ${ }^{1}$, Elijah Wostl2 ${ }^{2}$, Matt Crosslin ${ }^{3}$, T. Lisa Berry4, James P. Grover ${ }^{5}$
}

\begin{abstract}
Historical student data can help elucidate the factors that promote student success in mathematics courses. Herein we use both multiple regression and principal component analyses to explore ten years of historical data from over 20,000 students in an introductory college-level Algebra course in an urban American research university with a diverse student population in order to understand the relationship between course success and student performance in previous courses, student demographic background, and time spent on coursework. We find that indicators of students' past performance and experience, including grade-point-average and the number of accumulated credit hours, best predict student success in this course. We also find that overall final grades are representative of the entire course and are not unduly weighted by any one topic. Furthermore, the amount of time spent working on assignments led to improved grade outcomes. With these baseline data, our team plans to design targeted interventions that can increase rates of student success in future courses.
\end{abstract}

\section{Notes for Practice}

- Past studies have found that student grades are influenced by several factors, including student ability, student demographic background, and course specific factors.

- This study finds that student prior performance in past courses is the best predictor of final grade outcome in an introductory mathematics course.

- We recommend early interventions to target at-risk students, particularly students with low grade-point averages, students who are part time, and first semester students.

- We found that time spent on assignments is associated with higher grades. Therefore, to the extent possible, assignments should be given in an online format that incorporates a timestamp, thereby allowing instructors to identify in real-time students who may need intervention.

\section{Keywords}

Data mining, mathematics, learning analytics, Algebra, student ability.

Submitted: 15.11.2017 — Accepted: 24.04.2018 — Published: 11.12.2018

Corresponding author ${ }^{1}$ Email: oconnellk@si.edu Address: Department of Biology, University of Texas at Arlington, Box 19498, Arlington, TX 76019-0498, https://orcid.org/0000-0002-0464-9259

${ }^{2}$ Email:ewostl@uta.edu Address: Department of Biology, University of Texas at Arlington, Box 19498, Arlington, TX 76019-0498, 0000-00030746-007X

${ }^{3}$ Email:matt@uta.edu Address: Learning Innovation and Networked Knowledge Research Lab, University of Texas at Arlington, Box 19012, Arlington, Texas 76019-0012, https://orcid.org/0000-0003-0107-7715

${ }^{4}$ Email:Iberry@uta.edu Address: Address: Learning Innovation and Networked Knowledge Research Lab, University of Texas at Arlington, Box 19012, Arlington, Texas 76019-0012

5 Email:grover@uta.edu Address: Department of Biology, University of Texas at Arlington, Box 19498, Arlington, TX 76019-0498, https://orcid.org/0000-0003-2425-6927

\section{INTRODUCTION}

Mathematics courses demonstrate high rates of failure at a global scale (Faridhan, Loch, \& Walker, 2013). This is especially problematic in early mathematics courses, where a failing grade may significantly influence the probability of student retention and continuance (Arnold \& Pistilli, 2012). Thus, understanding the factors that promote success in early mathematics courses may assist higher education institutions with boosting retention and graduation rates. This is especially important for online or mixed-methods sections, which face much higher drop rates than traditional face-to-face (F2F) courses (Morris, Wu, \& Finnegan, 2005).

Additionally, United States retention rates at four-year degree-granting institutions is as low as $64.2 \%$ for students progressing from first to second year, while persistence to degree rates are as low as 36.4\% (American College Testing, 2012). 
One of the strongest predictors of student retention and graduation is first-year course success (Arnold \& Pistilli, 2012). This knowledge creates incentives for early interventions with students identified as high-risk, which should in turn increase rates of completion. The field of learning analytics provides opportunities for educators to uncover variables among students that help to predict success in courses (Siemens, 2012; Bakharia et al., 2016; Kovanović et al., 2017). Analyses of long-term course data (educational datamining), paired with learning analytics, may uncover patterns of learning among students that can be useful in designing targeted interventions (Baker \& Inventado, 2014; Berland, Baker, \& Blikstein, 2014). This study investigates the influence of various student and course specific factors on predicting student grades in mathematics courses by utilizing analytics and datamining.

Current research highlights several factors that may contribute to student success in a course, including student ability (measured as grade-point average [GPA] and test scores), student background (race, income, transfer credits), and course specific variables (instructor, semester; Snyder, Hackett, Stewart, \& Smith, 2003; Haynes, Mullins, \& Stein, 2005). Several of these variables have been explored in previous studies. Davidson (2015) found that the number of credit hours completed in a student's first year at a community college had a large positive impact on degree completion. In a similar light, Tempelaar, Rienties, and Giesbers (2015) found that prior mathematics experience was the best predictor of success in a college-level mathematics course. On the other hand, Diaz (2002) found that a student's prior GPA strongly influenced their persistence in an online mathematics course. Thus, we see that past studies have consistently identified prior course experience and prior GPA as strong predictors of a student's final course grade (Kuh, Kinzie, Buckley, Bridges, \& Hayek, 2006; Cavanaugh \& Jacquemin, 2015). Differences between student demographics have also been well studied. For example, Richardson (2008, 2012a, 2012b) found that minority students consistently performed worse than white students in the United Kingdom university system across fields in both F2F and online sections. This trend has also been well documented in Science, Technology, Engineering, and Mathematics (STEM) fields (Bahr, 2010; Kuh et al. 2006 and references therein; Ro \& Loya, 2015).

When courses are delivered online, several additional considerations arise. These are important to consider because online learning is rapidly growing at Universities around the world (Berk, 2013; Ali \& Smith, 2014; Mann \& Hennebbery, 2014). For example, online students are less likely than students enrolled in F2F courses to have satisfactory course outcomes; they have higher rates of withdrawal and reduced course satisfaction (Hauck, 2006; Smith et al., 2011; Ali \& Smith, 2015; Nfor, 2015; Callister \& Love, 2016). However, some studies have shown that online students may perform better than, or equal to F2F sections (Lattimore, 2012; Ali \& Smith, 2014; Cavanaugh \& Jacquemin, 2015; Biel \& Brame, 2016). Several studies suggest that this discrepancy in outcomes is explained by an interaction between instructional modality and a student's prior performance, producing different outcomes for online students of different skill levels (Bigelow, 2009; Lu \& Lemonde, 2013; Driscoll, Jicha, Hunt, Tichavsky, \& Thompson, 2017). Understanding what leads to student success in F2F and online sections is especially important in mathematics courses, where students have been shown to perform even more poorly than other subjects in online sections (Oliver, Kellogg, \& Patel, 2010).

Many recent research studies have examined related topics in massive open online courses (MOOCs), such as grade prediction (Gadhavi \& Patel, 2017; Meier, Xu, Atan, \& Van Der Schaar, 2015) and the use of intelligent tutoring systems to assist students (Crow, Luxton-Reilly, \& Wuensche, 2018; Kulik \& Fletcher, 2016). However, the educational context of these studies is not always transferrable to traditional university classroom scenarios. For example, the open nature of MOOCs makes data collection in those courses contextually different than data collected in smaller, private, selective enrollment courses. Additionally, the goal of this study was to look at student success through whatever lens the data presented, without limiting the lens to grades or specific intervention methods such as intelligent tutoring. Therefore, the analysis of predictive factors in historical data collected in traditional face-to-face and online mathematics courses at an urban American university was identified as lacking in the current literature.

Building on our literature analysis, this study investigates the influence of various student and course specific factors on predicting student final grades in an introductory mathematics course. This study investigates the following questions:

RQ1: What demographic variables best predict student success?

RQ2: Are the most predictive variables related to student performance, student background, or course specific factors?

RQ3: What is the effect of time spent on assignments and the final grade of students in online sections?

\section{METHODS}

\subsection{Dataset Generation and Preparation}

The authors and a team of graduate student assistants compiled two datasets. The first included anonymous student data spanning the academic terms of Fall 2009 to Spring 2017 from mathematics 1302, a College Algebra course at the University of Texas at Arlington. This is a large, public research university in an urban environment, with a diverse student population including a large proportion of first-generation students. Our data included students from traditional in-person lecture sections, entirely online sections, and mixed-methods sections. This dataset included 20,776 student entries across all semesters. Due to some students enrolling in the course multiple times, there were 3201 students repeated at least twice in the dataset (up to six entries). Our dataset included 20 predictor variables that we used to predict final grade (A-F,W; Table 1). We classified 
variables into three categories: course specific variables (instructor, term year, instruction mode), student performance (test scores, GPA), and student demographic background (Pell eligible, race, completed hours). We chose our variables to capture the effects of student background, prior knowledge, and any effects driven by the course or instructor outside of the student's control. Our decision on which variables to include in the analyses was based upon their availability. Therefore, we do not consider other variables that may also influence course outcome such as high school performance metrics.

Table 1. The 20 Predictor Variables Included in our Model

\begin{tabular}{ll}
\hline Variable & Details \\
\hline Academic term during enrollment & - \\
Instructional Mode & F2F, Online, Mixed \\
Semester during enrollment & Fall, Spring, Summer \\
Course Section & - \\
Instructor ID & - \\
Major college & College of Business etc. \\
Gender & Male, Female, Not specified \\
Academic load & Full, Part time \\
Race & African American, Hispanic/Latino, White, Asian-American, Multiple ethnicity, \\
& International student, Native American, Pacific Island, None \\
Academic Standing & Good, Probationary \\
Total transfer credit & \# credit hours \\
Transfer type & Some or none \\
Total completed credit hours & At course enrollment \\
Completed credit hours bin & $0-14$ or 15-29 \\
Pell status & Eligible, Not eligible, Did not apply for FAFSA \\
Cumulative GPA & At course enrollment \\
Prior college mathematics & Yes or no \\
SAT mathematics score & - \\
SAT cumulative score & - \\
ACT mathematics score & - \\
\hline
\end{tabular}

The second dataset encompassed online sections of the same course from the Fall 2013 semester to the Summer 2017 semester. These data included assignment, quiz, and exam grades, as well as the amount of time spent on each task. This course covered five chapters. Homework assignments ranged from 1-5 per chapter, with two quizzes for each chapter and three exams throughout the semester. One final exam was also included in the dataset, as well as the final grade for the course. There were 285 students included in this dataset. Demographic information was not included with these data, as we were only interested in the effects on the final grade of particular assignments and the amount of time spent.

\subsection{Data Exploration}

We began by exploring the demographic constitution of the students in our dataset. We primarily used Tableau Desktop V10.2.2 (Tableau Software, Seattle, WA) for data exploration. This dataset included 34 academic semesters (Fall, Spring, Summer), and 64 course sections taught by 59 instructors. Our dataset included $51.1 \%$ of students participating in face-to-face (F2F) sections, $33.8 \%$ of students online, and $15.1 \%$ of students in a mixed-mode section. The drop, fail, or withdraw rate (DFW) was 39.3\%. Additional summary statistics of interest are shown in Tables 2 and 3 (see Appendix). As an initial exploratory step, we assessed the data for significant differences between the course outcomes of each categorical grouping. Significant differences between predictor variables were quantified in SPSS using either a two-tailed t-test (for comparisons of two groups), or an ANOVA (for three or more groups). We conducted one-way ANOVAS, as well as multi-way ANOVAS for identified significant variables to investigate interactions between variables.

\subsection{Regression Analysis of Demographic Variables}

Multiple regression analyses were conducted using SPSS v.24.0.0.1 (IBM Corp., Armonk, NY). The automatic linear modelling tool was utilized to identify which features of student performance and background best predicted performance in the course. We first checked that our data did not violate any assumptions of multiple regression analysis. Model selection was then conducted using a forward stepwise approach based on the corrected Akaike information criterion (AICC). We crossvalidated the previous approach using the best-subsets model selection, as well as including all variables in our analysis without model selection. No significant differences were found between analyses. All other model parameters were left as default, 
including the automatic data preparation feature. This feature removes outlier values that are greater than three standard deviations away from the mean for any variable, replaces all missing values, and merges categories across individuals (binning) to maximize model fit based on AICC. All 20 predictor variables were included in our exploratory analysis. Each variable was coded numerically, and variables were classified accordingly as nominal or scalar. Each analysis attempted to predict the average grade, which included only $\mathrm{F}-\mathrm{A}$ scores scaled as $0-4$, or the final grade, which included students who had withdrawn (W-A, coded as 1-6). The program predicted the fit of the best model as a percentage based on the AICC score of that model. We also conducted a binary logistic regression of all variables to predict students who would pass or fail by coding DFW grades as 0 and all other grades as 1 .

\subsection{Principal Component Analysis and Regression of Assignment Scores}

We investigated the dataset to see if any subsets of assignments and quizzes were more strongly associated with the final grade than would be expected by random chance. To do so, we conducted a series of principal component analyses in SPSS, comparing individual assignment grades for all assignments, and the final grade, as well as individual assignment grades, time spent on the assignment, and the final grade. We also conducted a multiple regression analysis in SPSS to examine the relationship between time spent on an introductory assignment, median time spent per assignment, and the final grade.

\section{Results}

\subsection{Data Exploration}

We began our analysis by exploring the distribution and mean grades of several predictor variables identified as significant in past studies, with an emphasis on race and instruction mode (Tables 1 and 3). We first investigated the four largest racial categories for all instruction modes: Black/African American, White, Hispanic/Latino, and Asian-American (Tables 2 and 3). We excluded other racial categories because sample sizes were less than 1000 students. The category of "not-specified" was also excluded for this analysis. Initially, we found differences in the mean grades and average GPA of each race (Table 3). Mean grades $(1=\mathrm{D}, 2=\mathrm{C}, 3=\mathrm{B}, 4=\mathrm{A})$ were 1.6 (standard deviation [stdev] $=1.4, \mathrm{n}=2382)$ for Black/African American students, $2.2(\operatorname{stdev}=1.4, \mathrm{n}=5779)$ for White students, $1.9(\mathrm{stdev}=1.4, \mathrm{n}=3298)$ for Hispanic/Latino students, and $2.6(\mathrm{stdev}$ $=1.3, \mathrm{n}=1373$ ) for Asian-American students (Figure 1A-B). We used a one-way ANOVA to confirm that these mean grades were significantly different $(p<0.001)$. The ANOVA testing for differences in GPA among racial groups was also significant $(p<0.001)$.

Interestingly, we were able to identify patterns suggesting an interaction between race and instruction mode (Figure 1BC). By plotting the proportion of each grade received by students in a certain racial category, and separating these by instruction mode, we found that racial groups had different propensities (in terms of proportion of students) for dropping the course, and that this propensity differs between online and F2F sections (Figure 1C). Among F2F Black/African American students, the distribution of grades, including W's, evenly distributed across grade categories, although fewer students received A's (Figure 1C). Yet among online students we observed large number of W's and F's, while other grades appeared unimodal (Figure 1C). This indicates that Black/African American students are more likely to drop or fail the course when taking an online section (Figure 1C). Among White students, the trend is similar. Grades among F2F students show no clear pattern, although the most common grade was a B. In online sections, more students withdrew than received any other grade (Figure 1C). However, students who did not withdraw were more likely (as a proportion of total students) to receive a C-A grades than an F or D grades (Figure 1C). Among Hispanic/Latino and Asian-American students, a larger proportion of students dropped the course in online sections than in the F2F sections (Figure 1C). Interestingly, 73\% of Asian-American students in the F2F course received a grade higher than a D, compared with an average of 54\% in the other racial groups (Figure 1C). Thus, we see that racial groups responded with different distributions of grades in F2F and online sections, and that the propensity to drop or fail the course was much higher in online sections, when measured as a proportion of total students. 

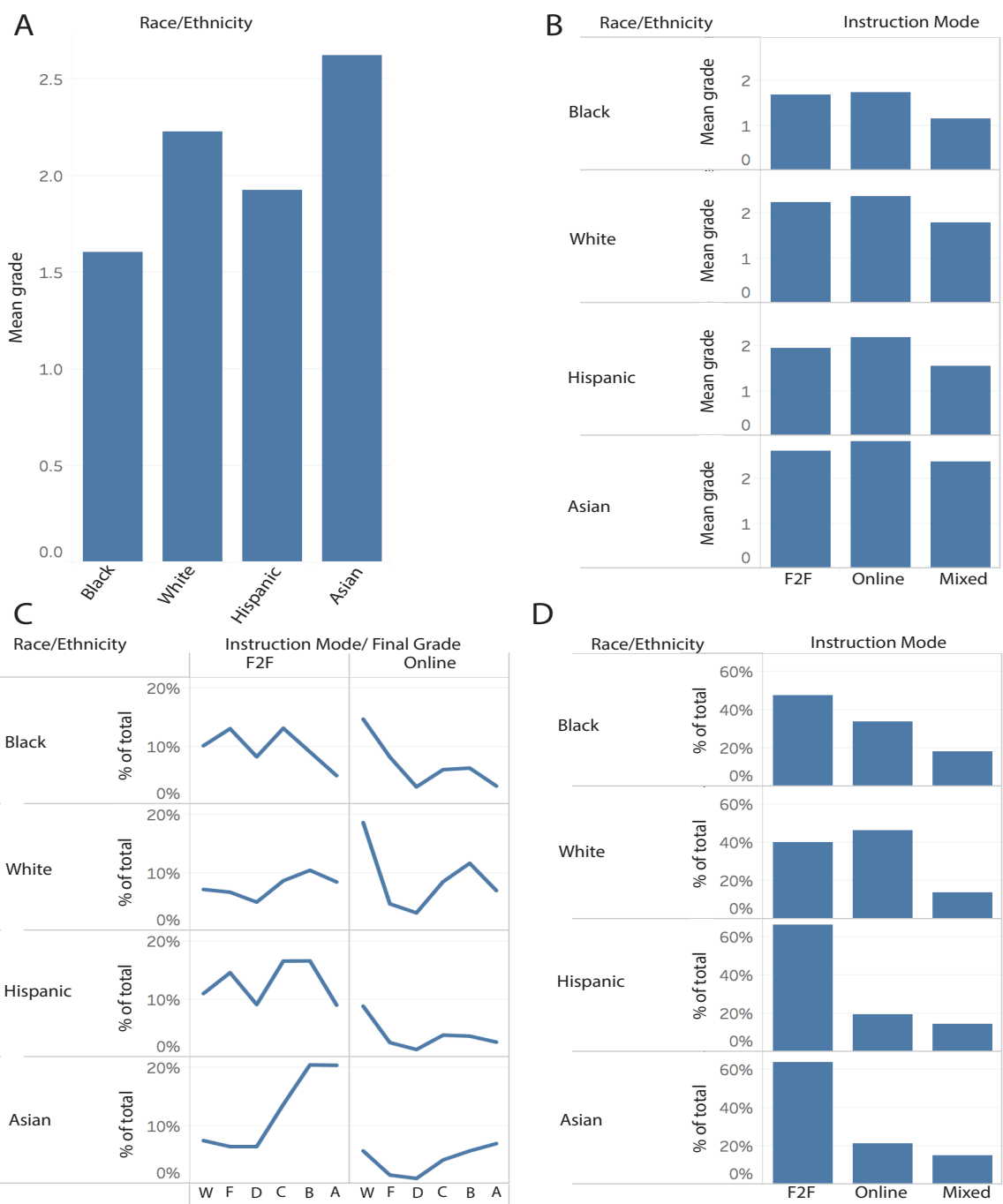

Figure 1. Associations of race and instruction mode. A) Mean grade for each of the four largest racial groups in this study. B) Mean grade for each racial group divided by instruction mode. C) Distributions of grades for each racial group split into Face to Face (F2F) and online sections. Mixed methods had low enrolment and were thus excluded from figures showing percent of total enrollment. D) Enrollment differences between racial groups in F2F, online, and mixed methods sections.

We also observed large differences in the propensity of racial groups to enroll in different instruction modes (Figure 1D). For example, Hispanic/Latino, and Asian-American students enrolled in higher numbers in F2F sections than in online sections (Figure 1D). Black/African American students were almost equally likely to enroll in online verses F2F sections, while White students were more likely to enroll in online sections (Figure 1D). When we sorted this data by gender we observed that among Black/African American students, females were equally likely to take the course F2F vs. online, but males were more likely to take the course F2F (Figure 2). Among White students, males were more likely to participate in F2F sections, while females were much more likely to take the course online (Figure 2). In both Hispanic/Latino and Asian-American students, both genders were more likely to take the course F2F (Figure 2). 


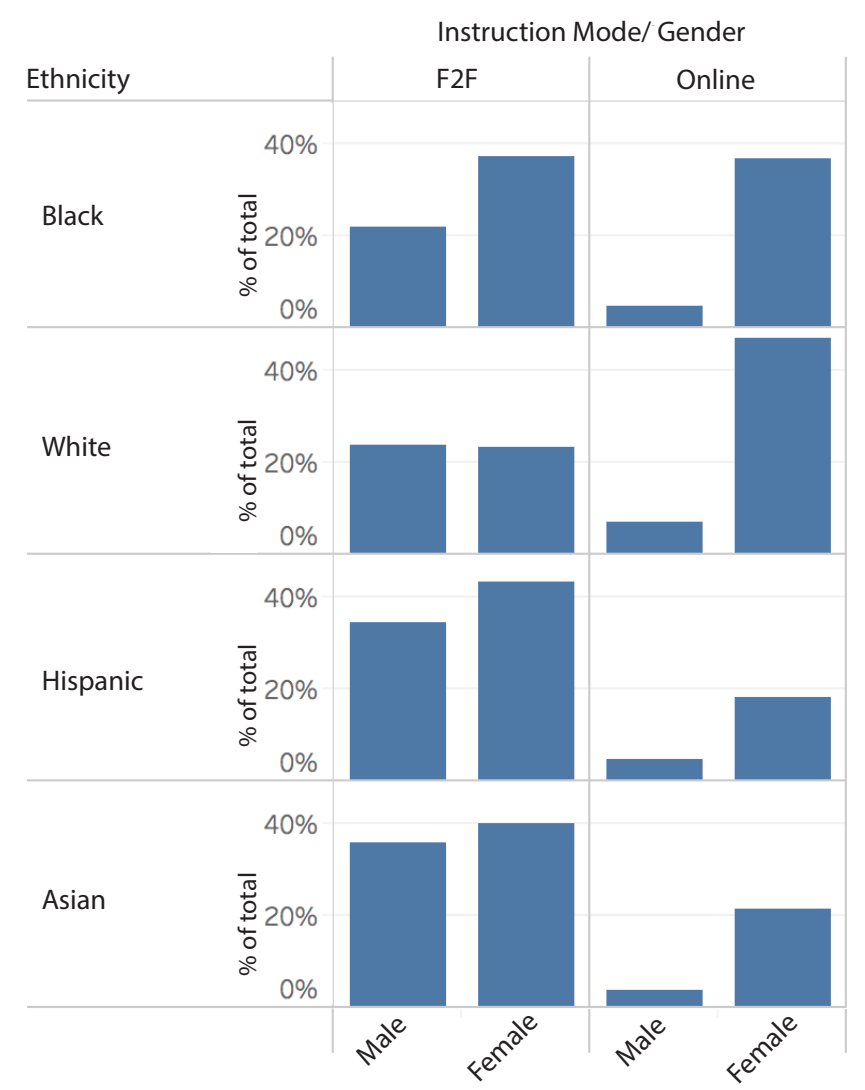

Figure 2. The interaction of instruction mode, race, and gender. This figure shows the propensity of each gender within each racial group to enroll in each instruction mode.

We also explored differences in grade distributions and means between different instruction modes. We plotted the distribution of scores for each instruction mode, and found that a higher proportion of students dropped the course in the online (35\%) or mixed mode (23.4\%) sections than in the F2F section (14.7\%; Figure 3). We calculated the mean grade excluding withdrawals and found a similar mean grade in F2F (mean $=2.1$, stdev $=1.4, \mathrm{n}=8876)$ and online (mean $=2.2$, stdev $=1.4, \mathrm{n}$ $=4555)$ or mixed mode $($ mean $=1.64$, stdev $=1.4, \mathrm{n}=2358)$.

We explored other student variables such as academic load, and found that full-time students had a mean grade of 2.1 $(\operatorname{stdev}=1.4, \mathrm{n}=10,832)$ compared with a mean grade of $2.0(\mathrm{stdev}=1.4, \mathrm{n}=4957)$ for part-time students (t-test nonsignificant). We did observe a significant difference in mean grade based on student academic standing. Students in good standing received a mean grade of $2.4($ stdev $=1.2, \mathrm{n}=12,385)$ compared with those with a probationary record scoring 0.7 $(\operatorname{stdev}=1.04, \mathrm{n}=3401)$ on average $(p<0.001)$. The distribution of grades for students of good and poor standing is also quite different, with students in good standing more likely to drop the course, but students with probationary records more likely to fail than to receive any other score (Figure 4A). Students who had not previously enrolled in a college-level mathematics course scored better than those who had previous college mathematics credits (mean $=2.2, \operatorname{stdev}=1.4, \mathrm{n}=10,201 \mathrm{vs}$. mean $=$ $1.8, \mathrm{stdev}=1.4, \mathrm{n}=5588, p<0.001)$. Yet, transfer credit was not a significant predictor of final grade, with an average grade of $2.1(\operatorname{stdev}=1.4, \mathrm{n}=5993)$ for students without transfer credit, and $2.0($ stdev $=1.4, \mathrm{n}=9793)$ for students with transfer credit (t-test non-significant). However, we did find that the distributions of grades were quite different for these two groups, with transfer students much more likely to withdraw or fail when measured as a proportion of the total (Figure 4B). We also explored the role of income on grades and found a large difference between income groups. Pell-eligible students (those receiving need-based Federal aid) received a mean grade of $1.8(\operatorname{stdev}=1.4, \mathrm{n}=6768)$, compared with $2.1(\operatorname{stdev}=1.4, \mathrm{n}=$ 4200) in non-eligible students, and $2.4($ stdev $=1.3, \mathrm{n}=4815)$ in students who did not complete a Free Application for Federal Student Aid (FAFSA; $p<0.001$ ). Yet, the distributions of grades for these three groups were similar (Figure 4C). 


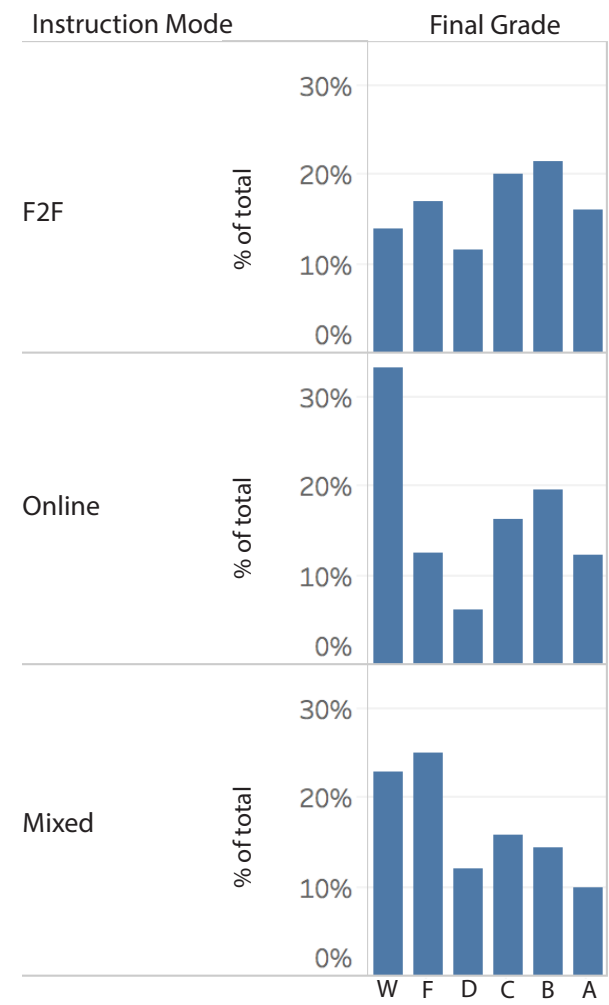

Figure 3: Grade distributions for each instruction mode.

We further tested these patterns using a multi-way ANOVA that investigated interactions between race, gender, and instruction mode. When predicting the mean grade, we recovered no significant interactions, but when predicting final grades (grade "W" included), we recovered a significant interaction between gender and instruction mode $(p=0.003)$. Thus, although different racial groups, and the two gender groups, behave differently in terms of dropping or failing the course, the only differences that predict the final grade are those associated with the interaction of gender and instruction mode.

Nonetheless, there were several factors that did not associate with final grade across all analyses. One of these factors was gender. Not only did gender never contribute to any of the multiple regression models presented in the next section, but we also observed no relationship between gender and instruction mode (Figure 4D). There was no significant different in mean grades between genders as tested using a t-test, but we did observe much higher enrollment in the course by females $(\mathrm{n}=$ $10,137)$ than by males $(\mathrm{n}=5649)$. This imbalance is likely explained by the disproportionate number of nursing students enrolled in this course (38.6\%; Figure 5), who were more likely to be female.

\subsection{Multiple Regression}

After exploring the distribution patterns and testing the difference in means of different variables, we used multiple regression analyses to determine the contribution of each variable to the prediction of final grade (Table 4). The first analysis used all predictor variables to predict the average score $(\mathrm{A}-\mathrm{F})$. Grades were treated as a discrete quantitative variable by coding numerically from $1-5$. Our final model had a $57.7 \%$ accuracy fit to the data based on the AICc value. The program weighed the contribution of each predictor variable to the total model fit. Cumulative GPA had the greatest contribution to the model, explaining $54 \%$ of the variance. Cumulative credit hours explained $16 \%$ of the variance. These were followed by course section $(8 \%)$, major college (4\%), ethnicity (2\%), academic standing (2\%), ACT mathematics score (1\%), and instruction mode (1\%). Thus, GPA and cumulative credit hours explained most of the variance, but several other variables contributed to the model. The analysis was repeated to predict the final grade, which included students who had dropped the course before the end of the semester (grade W). This model fit the data with an accuracy score of $46.8 \%$. Cumulative credit hours explained $50 \%$ of the variance, while the course section explained 13\%, academic load 12\%, GPA $8 \%$, SAT mathematics 5\%, College 4\%, ACT mathematics $2 \%$, Ethnicity $2 \%$, academic standing $1 \%$, and academic semester $1 \%$.

Finally, we wanted to understand what factors in the data best predicted a student passing or failing the course. Using a logistic regression, we found that the academic load of the student best predicted their passing of the course $(\operatorname{Exp}(B)=15.5)$, followed by completed course hours $(\operatorname{Exp}(B)=1.6)$ and SAT mathematics test score $(\operatorname{Exp}(B)=1.0)$. 


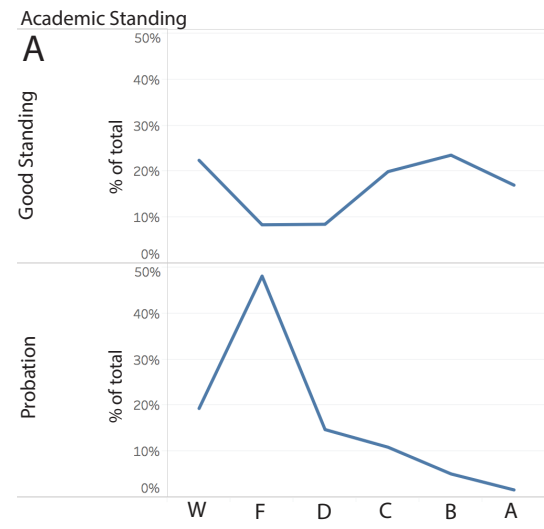

C
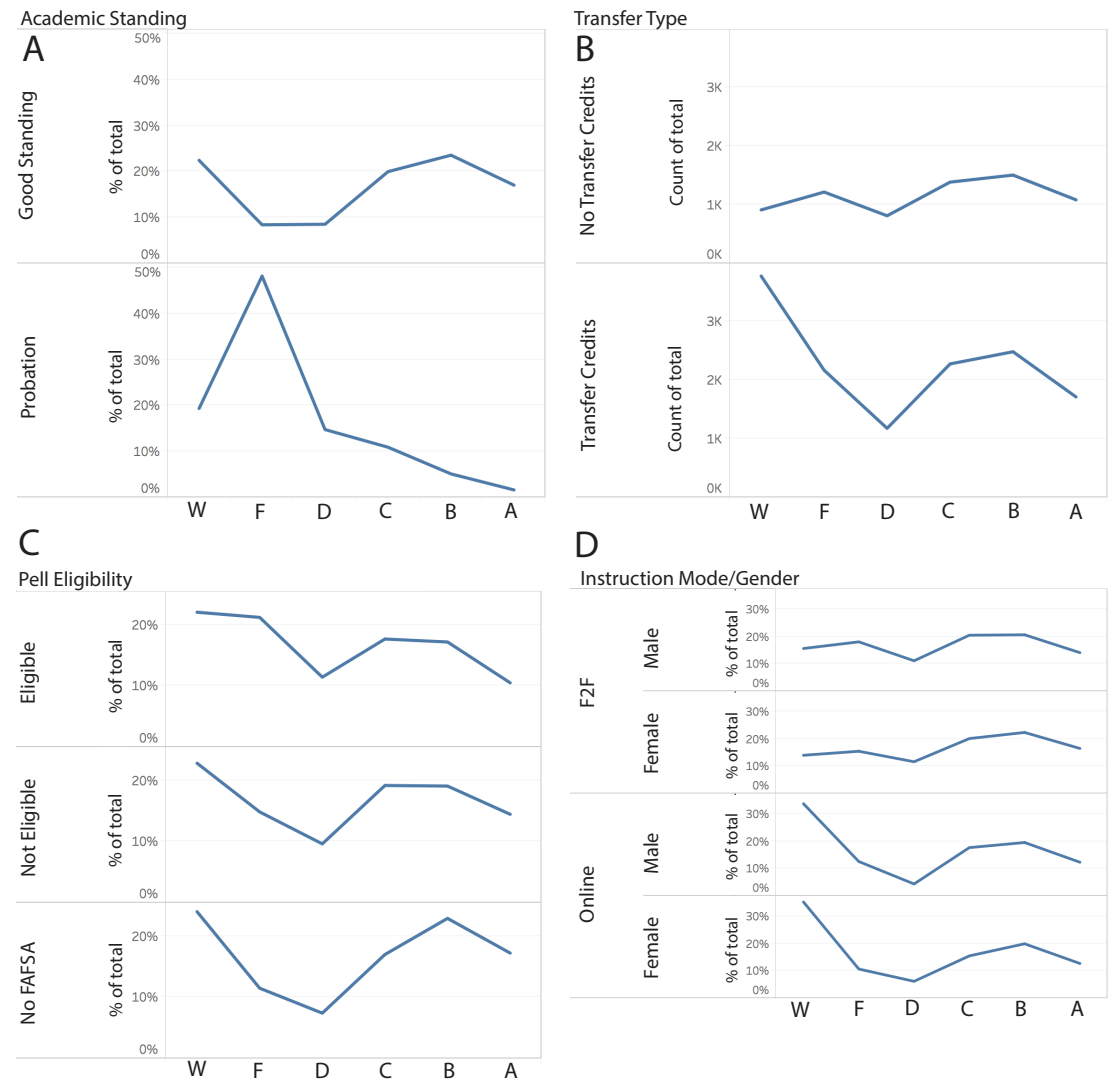

Figure 4. Grade distributions for miscellaneous predictor variables. A) Grade distributions for students in good and poor academic standing. B) Grade distributions for transfer and traditional students. C) Grade distributions for students based on Pell eligibility status, hereserving as a proxy for income. D) Grade distributions for male and female students divided by instruction mode.

Based on these findings, we used simple linear regressions to better understand the influence of GPA and cumulative hours on student course success. We found that for a student to pass the course with at least a D grade, they would need a 2.19 GPA. However, when we removed students who had withdrawn from the course, the GPA needed dropped to 1.55. As for cumulative hours, regardless of the instruction mode, far more students took the course in their first semester than in their second semester $(18,504$ verses 2,264$)$. This discrepancy suggests that our results should be interpreted with some caution. However, second semester students performed better in the course, regardless of instruction mode, race, or gender (mean $=1.9$, stdev $=1.4, \mathrm{n}=$ 13,637 vs. mean $=2.8$, stdev $=1.0, \mathrm{n}=2149$, t-test $p<0.001$ ).

\subsection{Principal Component Analysis and Regression of Assignment Scores}

Almost all the variation in grades was attributable to a single principal component (eigenvalue $=25.25,26$ variables). The loading scores of each assignment onto this first component roughly increased as the number of assignments increased. Overall the indication was that the final grade was not overly influenced by any one assignment or quiz, and, unsurprisingly, that students who performed well in the latter part of the semester did better in the class overall. The multiple-regression analysis found a significant relationship $(p<0.001)$ between the median time spent on each assignment and the final grade. Thus, students who spent more time working on assignments received a better final grade than those who spent less time.

\section{Discussion}

Exploration of the data identified several predictor variables associated with large differences in final grade. We found substantial differences between grades based on instruction mode, racial category, academic standing, and previous mathematics experience. Most interesting perhaps is the difference in the distribution of these grades based on certain factors such as race and instruction mode. We found that students from different racial groups, as well as students enrolled in different instruction modes, had different propensities to drop rather than fail the course. Also, we found that different racial groups were more likely to enroll in the online sections, and that this differed by gender within racial groups. Yet, we found no significant differences in grades based on gender. We were surprised in particular to find that students with no prior college 
mathematics experience scored better on average than those with previous mathematics enrollment. This finding conflicted with that of Tempelaar et al. (2015), who found that prior mathematics experience was a strong positive predictor of performance in college mathematics courses. We hypothesize that this finding is indicative of the students who enroll in introductory mathematics at the University of Texas at Arlington, where no prerequisite mathematics courses are required. Because the course under consideration is introductory, those with prior college mathematics experience likely took a remedial course before entering this course and thus these may be students already at a disadvantage for college-level mathematics courses.

Table 4. Grade Distribution for Selected Predictive Factors*

\begin{tabular}{lcccccccccc}
\hline Section & $\mathrm{W}$ & $\mathrm{F}$ & $\mathrm{D}$ & $\mathrm{C}$ & $\mathrm{B}$ & $\mathrm{A}$ & $\mathrm{N}$ & $\begin{array}{c}\text { Mean } \\
\text { grade }\end{array}$ & DFW & GPA \\
\hline All & 22.8 & 16.5 & 9.7 & 17.9 & 19.5 & 13.6 & 20460 & 3.4 & 39.3 & 2.7 \\
F2F & 4 & 9.3 & 9.5 & 21.9 & 29 & 26.0 & 10403 & 3.6 & 13.3 & 2.5 \\
Online & 11.3 & 8 & 5.9 & 20.5 & 31 & 23.4 & 6983 & 3.1 & 19.3 & 2.9 \\
Mixed & 7.7 & 16.4 & 11.8 & 20.6 & 23.7 & 19.7 & 30773 & 3 & 24.1 & 2.4 \\
Black & 25 & 23.2 & 11.9 & 18.63 & 13.9 & 7.3 & 3188 & 1.6 & 48.2 & 2.4 \\
White & 25.5 & 12.8 & 8.5 & 17 & 21.5 & 14.8 & 7761 & 2.2 & 38.3 & 2.9 \\
Hispanic & 20.6 & 18.2 & 10.7 & 20 & 19.7 & 10.9 & 4151 & 1.9 & 38.8 & 2.5 \\
Asian- & & & & & & & & & & \\
American & 13.1 & 8.9 & 7.9 & 17.2 & 25.9 & 27 & 1580 & 2.6 & 22 & 2.8 \\
\hline
\end{tabular}

* All values represent percentages except for the mean grade $(0-4=\mathrm{F}-\mathrm{A})$, and GPA (0-4.0). W = Withdrawal.

Linear modelling with 20 predictor variables revealed that many of the factors we had previously explored had small effects on the students' final grades. The two factors consistently recovered as significant predictors of final grade were the student's GPA, the number of cumulative credit hours a student had, academic load, and course section. The first two variables are positively correlated, as students with more course hours have had more time to accumulate GPA points. These findings support two ideas. The first is that the students' past performance is predictive of future success. Next, second semester students perform better because they have had additional time to develop the study and self-regulation skills that they need to perform well in this course. This emphasizes the need to identify students who have developed skills necessary for success, and to find ways to encourage those who do not yet have these skills to develop them. Due to our finding of only a minor difference in scores between students with or without transfer credits $(2.04,2.07)$, we do not expect that transfer credits are driving this trend. Multiple regression analyses also support the finding that full-time students perform better than part-time students. These findings may also correspond to our finding that increased time spent on course tasks in the online section (Section 3.3) led to higher mean grades. Finally, our study found that the course section contributed significantly to the linear regression model predicting final grade (grade "W" included). Although many instructors taught several sections in our dataset, no instructor effect was recovered. This suggests that the cohort of students enrolled in a specific course may make a large difference in student grades and may provide a fruitful avenue for future research.

Universities are often interested in creating interventions to prevent students from dropping or failing, as these grades may have detrimental effects on a student's future success. However, the mean grade across a demographic group may not capture a signal of the difference in the propensity of dropping, or staying in the course. For example, this study did not recover a statistical difference in the mean grade for transfer students (2.04) compared to traditional students (2.07). Thus, we could expect that these two populations would exhibit similar grade distributions. However, Figure 4D suggests that transfer students are much more likely to drop than to fail, while traditional students are more likely to fail than to drop. Thus, interventions can be designed differently for transfer and traditional students to target these behaviour patterns (Berger \& Malaney, 2003). We observed similar trends in different racial groups, especially when broken down by instruction mode (Figure 3). This sort of information could be used by educators to design interventions that offer certain students additional help to reduce DFW rates (Tinto, 1975; Onah, Sinclair, \& Boyatt, 2014). On the other hand, we found that income categories (Pell eligibility) had different mean grades, but the distribution of these grades was similar, indicating that lower- and upper-income students do not behave differently (in terms of their propensity to drop or "stick it out"), but that higher-income students do perform better on average (Figure 4C). This may have more to do with prior experience during high school. Future studies may be able to conduct similar analysis with the inclusion of high school information to test this hypothesis. 


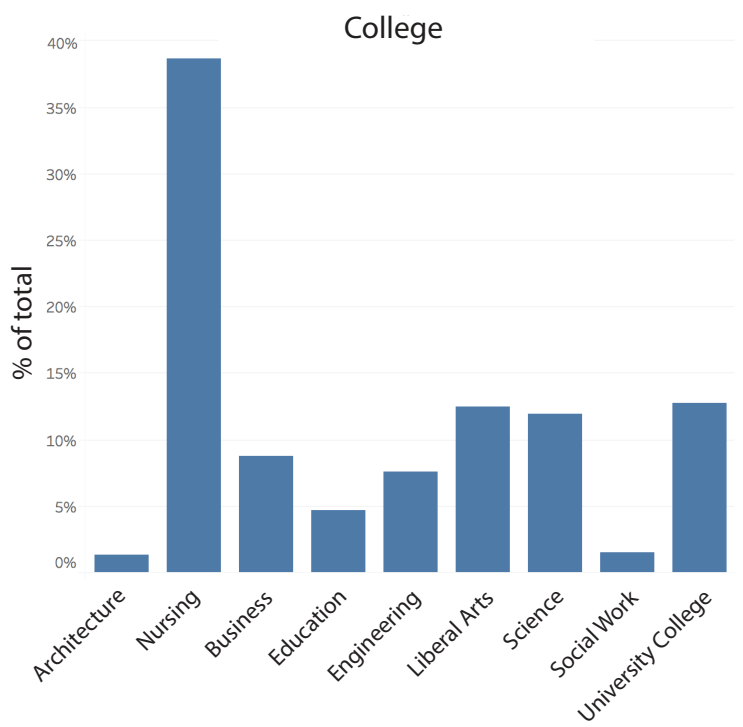

Figure 5. Proportion of students belonging to each academic college. Nursing students contributed the largest proportion of enrolled students in this study.

Our study corroborated the findings of many past studies, especially in showing that online and minority students performed more poorly than F2F and White or Asian-American students. However, we also found that when analyzed together, race and instruction mode contributed little to the likelihood of a student succeeding in the course. Rather, the student's GPA, prior course credits, and academic load best predicted a high final grade. This suggests that new and low-performing students should be targeted for intervention rather than certain racial, gender, or instruction mode categories (Heublein, 2014; Stinebrickner \& Stinebrickner, 2014). Perhaps the driver of lower online scores has more to do with the types of students participating in these courses, rather than the format of the course. Yet we found that students in online courses had lower average cumulative hours $(\mathrm{F} 2 \mathrm{~F}=9.6, \mathrm{stdev}=4.7, \mathrm{n}=10,613 ;$ Online $=6.8, \mathrm{stdev}=5.3, \mathrm{n}=7017$; Mixed $=8.6, \mathrm{stdev}=5.0, \mathrm{n}=3138 ; p<0.001)$, but higher average GPAs $(\mathrm{F} 2 \mathrm{~F}=2.5$, stdev $=1.0, \mathrm{n}=10,613$; Online 2.9, $\operatorname{stdev}=1.0, \mathrm{n}=7017$; Mixed $=2.4$, stdev $=0.9, \mathrm{n}=$ $3138 ; p<0.001)$.

Our analysis of online students found that no individual assignment or quiz significantly influenced the final grade. Rather, the amount of time students spent working on assignments was the best predictor of final grade. This suggests that students who put more effort into the course performed better. Nonetheless, it can be misleading to correlate time spent with effort. For this reason, students who spend more time could be those who are working harder to understand the material, or those most engaged with the course (Zacharis, 2015). In either case, we would expect a positive relationship between effort (time spent) and grade. Alternatively, this could represent the demographic who are struggling the most with the material, though if this were true, we would expect an inverse relationship between time spent and overall grade. Past research primarily supports the first hypothesis, that students who work harder in the course (more time spent) perform better (Cheema \& Sheridan, 2015; Farkas, Mazurek, \& Marone, 2015).Overall, this relationship suggests that any effort on the part of the instructor that encourages students to spend more time with the material may prove beneficial. It also suggests a way for instructors to take immediate action and points to a region of pedagogical methodology that needs further investigation and development. Regression analysis suggested that full-time students were more likely to pass the course than part-time students, presumably because they are working less at an external job.

\section{Conclusions and Implications for Practitioners}

Practitioners and researchers need to be careful in trying to apply a "one size fits all" approach, as this study found that course section also had a notable effect on student performance. This suggests that some level of performance is section/course specific rather than student specific (Gašević, Dawson, Rogers, \& Gasevic, 2016). Additionally, it should be noted that these results are from a study at one university with a higher diversity in student population than many other universities, so results may not transfer to other institutions. However, practitioners wishing to act upon these results should primarily focus on a student's GPA, number of incoming credit hours, and academic load to predict student success and develop early interventions. We suggest that academic advisors could be equipped with this knowledge to encourage at-risk students (part-time, new, and low GPA) to seek tutoring or other help. In addition, at-risk students could be identified and targeted by instructors using new online tools (Pardo et al., 2017). Future research projects could identify students who have taken a prior mathematics courses 
and investigate the specific factors or skills that contribute to current success. Finally, investigators may be able to target students based on the amount of time they are spending on assignments to better understand what time spent means for student course performance.

\section{Declaration of Conflict of Interest and Funding}

The authors declare no potential conflicts of interest and no financial support with respect to the research, authorship, and/or publication of this article.

\section{References}

Ali, A., \& Smith, D. (2014). Comparing students performance in online versus face-to-face courses in computer literacy courses. Competition Forum, 12(2), p. 118.

Ali, A., \& Smith, D. T. (2015). Comparing social isolation effects on students attrition in online versus face-to-face courses in computer literacy. Issues in Informing Science and Information Technology, 12, 11-20. https://dx.doi.org/10.28945/2174

American College Testing. (2012). National collegiate retention and persistence to degree rates. Iowa City, IA: http://www.act.org/research/policymakers/pdf/retain_2012.pdf

Arnold, K. E., \& Pistilli, M. D. (2012). Course signals at Purdue: Using learning analytics to increase student success. Proceedings of the $2^{\text {nd }}$ International Conference on Learning Analytics and Knowledge (LAK '12), 29 April-2 May 2012, Vancouver, BC, Canada (pp. 267-270). New York: ACM. https://dx.doi.org/10.1145/2330601.2330666

Bahr, P. R. (2010). Preparing the underprepared: An analysis of racial disparities in postsecondary mathematics remediation. The Journal of Higher Education, 81, 209-237. http://dx.doi.org/10.1353/jhe.0.0086

Baker, R. S., \& Inventado, P. S. (2014). Educational data mining and learning analytics. In Learning analytics, 61-75. New York: Springer. https://dx.doi.org/10.1017/CBO9781139519526.016

Bakharia, A., Corrin, L., de Barba, P., Kennedy, G., Gašević, D., Mulder, R., ... \& Lockyer, L. (2016). A conceptual framework linking learning design with learning analytics. Proceedings of the 6th International Conference on Learning Analytics and Knowledge (LAK'16), 25-29 April 2016, Edinburgh, UK (pp. 329-338). New York: ACM. https://dx.doi.org/10.1145/2883851.2883944

Berger, J. B., \& Malaney, G. D. (2003). Assessing the transition of transfer students from community colleges to a university. NASPA Journal, 40, 1-23. http://dx.doi.org/10.2202/0027-6014.1277

Berk, R. A. (2013). Face-to-face versus online course evaluations: A “consumer's guide” to seven strategies. Journal of Online Learning and Teaching, 9, 140.

Biel, R., \& Brame, C. J. (2016). Traditional versus online biology courses: Connecting course design and student learning in an online setting. Journal of Microbiology \& Biology Education, 17, 417. http://dx.doi.org/10.1128/jmbe.v17i3.1157

Bigelow, C. A. (2009). Comparing student performance in an online versus a face to face introductory Turfgrass science course: A case study. NACTA Journal, 53, 1-7.

Berland, M., Baker, R. S., \& Blikstein, P. (2014). Educational data mining and learning analytics: Applications to constructionist research. Technology, Knowledge and Learning, 19, 205-220. http://dx.doi.org/ 10.1007/s10758-0149223-7

Callister, R. R., \& Love, M. S. (2016). A comparison of learning outcomes in skills-based courses: Online versus face-toface formats. Decision Sciences Journal of Innovative Education, 14, 243-256. http://dx.doi.org/10.1111/dsji.12093

Cavanaugh, J., \& Jacquemin, S. J. (2015). A large sample comparison of grade based student learning outcomes in online vs. face-to-face courses. Online Learning, 19.

Cheema, J. R., \& Sheridan, K. (2015). Time spent on homework, mathematics anxiety and mathematics achievement: Evidence from a US sample. Issues in Educational Research, 25, 246-259.

Crow, T., Luxton-Reilly, A., \& Wuensche, B. (2018). Intelligent tutoring systems for programming education: A systematic review. Proceedings of the $20^{\text {th }}$ Australasian Computing Education Conference (ACE '18), 30 January-2 February 2018, Brisbane, QLD, Australia (pp. 53-62). New York: ACM. http://dx.doi.org/10.1145/3160489.3160492

Davidson, J. C. (2015). Precollege factors and leading indicators: Increasing transfer and degree completion in a community and technical college system. Community College Journal of Research and Practice, 39, 1007-1021. http://dx.doi.org/ $10.1080 / 10668926.2014 .919619$

Diaz, D. (2002). Online drop rates revisited. The Technology Source. http://ts.mivu.org/default.asp?show=article\&id=981

Driscoll, A., Jicha, K., Hunt, A. N., Tichavsky, L., \& Thompson, G. (2012). Can online courses deliver in-class results? A comparison of student performance and satisfaction in an online versus a face-to-face introductory sociology course. Teaching Sociology, 40, 312-331. http://dx.doi.org/ 10.1177/0092055X12446624

Faridhan, Y. E., Loch, B., \& Walker, L. (2013). Improving retention in first-year mathematics using learning analytics. Proceedings of the 30th Annual Conference of the Australasian Society for Computers in Learning in Tertiary Education (ASCILITE 2013) 1-4 December 2013, Sydney, Australia (pp. 278-282). Australasian Society for Computers in Learning in Tertiary Education.

Farkas, G. J., Mazurek, E., \& Marone, J. R. (2016). Learning style versus time spent studying and career choice: Which is 
associated with success in a combined undergraduate anatomy and physiology course? Anatomical Sciences Education, 9, 121-131. http://dx.doi.org/ 10.1002/ase.1563

Gašević, D., Dawson, S., Rogers, T., \& Gasevic, D. (2016). Learning analytics should not promote one size fits all: The effects of instructional conditions in predicting academic success. The Internet and Higher Education, $28,68-84$. https://dx.doi.org/10.1016/j.iheduc.2015.10.002

Gadhavi, M., \& Patel, C. (2017). Student final grade prediction based on linear regression. Indian Journal of Computer Science Engineering, 8(3), 274-279.

Hauck, W. E. (2006). Online versus traditional face-to-face learning in a large introductory course. Journal of Family and Consumer Sciences, 98, 27.

Haynes, A. F., Mullins, A. G., \& Stein, B. S. (2004). Differential models for math anxiety in male and female college students. Sociological Spectrum, 24, 295-318. http://dx.doi.org/10.1080/02732170490431304

Heublein, U. (2014). Student drop-out from German higher education institutions. European Journal of Education, 49, 497513. http://dx.doi.org/ 10.1111/ejed.12097

Kovanović, V., Joksimović, S., Katerinopoulos, P., Michail, C., Siemens, G., \& Gašević, D. (2017). Developing a MOOC experimentation platform: Insights from a user study. Proceedings of the 7th International Conference on Learning Analytics and Knowledge (LAK '17), 13-17 March 2017, Vancouver, BC, Canada (pp. 1-5). New York: ACM. http://dx.doi.org/10.1145/3027385.3027398

Kuh, G. D., Kinzie, J. L., Buckley, J. A., Bridges, B. K., \& Hayek, J. C. (2006). What matters to student success: A review of the literature (Vol. 8). Washington, DC: National Postsecondary Education Cooperative.

Kulik, J. A., \& Fletcher, J. D. (2016). Effectiveness of intelligent tutoring systems: A meta-analytic review. Review of Educational Research, 86(1), 42-78. https://dx.doi.org/10.3102/0034654315581420

Lattimore, T. N. (2012). Reading online: Comparing the student completion frequencies in an instructor-led face-to-face versus online developmental reading course (Unpublished doctoral dissertation). Capella University, Minneapolis, $\mathrm{MN}, \mathrm{USA}$.

Lu, F., \& Lemonde, M. (2013). A comparison of online versus face-to-face teaching delivery in statistics instruction for undergraduate health science students. Advances in Health Sciences Education, 18, 963-973. http://dx.doi.org/ 10.1007/s10459-012-9435-3

Mann, J. T., \& Henneberry, S. R. (2014). Online versus face-to-face: Students' preferences for college course attributes. Journal of Agricultural and Applied Economics, 46, 1-19. http://dx.doi.org/10.1017/S1074070800000602

Meier, Y., Xu, J., Atan, O., \& Van Der Schaar, M. (2015). Personalized grade prediction: A data mining approach. Proceedings of the 15 th IEEE International Conference on Data Mining (ICDM 2015), 14-17 November 2015, Atlantic City, NJ, USA (pp. 907-912). IEEE Computer Society. http://dx.doi.org/ 10.1109/ICDM.2015.54

Morris, L. V., Wu, S. S., \& Finnegan, C. L. (2005). Predicting retention in online general education courses. The American Journal of Distance Education, 19, 23-36. http://dx.doi.org/10.1207/s15389286ajde1901_3

Nfor, S. K. (2015). Online versus face-to-face nutrition courses at a community college: A comparative study of learning outcomes (Unpublished doctoral dissertation). University of the Incarnate Word, San Antonio, TX, USA.

Oliver, K., Kellogg, S., \& Patel, R. (2010). An investigation into reported differences between online math instruction and other subject areas in a virtual school. Journal of Computers in Mathematics and Science Teaching, $29,417-453$. http://dx.doi.org/ 10.11139/cj.29.2.269-296

Onah, D. F., Sinclair, J., \& Boyatt, R. (2014). Dropout rates of massive open online courses: Behavioural patterns. Proceedings of the $6^{\text {th }}$ International Conference on Education and New Learning Technologies (EDULEARN14), 7-9 July 2014, Barcelona, Spain (pp. 5825-5834). Valencia, Spain: International Academy of Technology, Education and Development (IATED). http://dx.doi.org/10.13140/RG.2.1.2402.0009

Pardo, A., Martínez-Maldonado, R., Buckingham Shum, S., Schulte, J., McIntyre, S., Gašević, D., ... \& Siemens, G. (2017). Connecting data with student support actions in a course: A hands-on tutorial. Proceedings of the 7th International Conference on Learning Analytics and Knowledge (LAK '17), 13-17 March 2017, Vancouver, BC, Canada (pp. 522523). New York: ACM. http://dx.doi.org/10.1145/3027385.3029441

Richardson, J. T. (2008). The attainment of ethnic minority students in UK higher education. Studies in Higher Education, 33, 33-48. http://dx.doi.org/10.1080/03075070701794783

Richardson, J. T. (2012a). The attainment of white and ethnic minority students in distance education. Assessment $\&$ Evaluation in Higher Education, 37, 393-408. http://dx.doi.org/10.1080/02602938.2010.534767

Richardson, J. T. (2012b). Face-to-face versus online tuition: Preference, performance and pass rates in white and ethnic minority students. British Journal of Educational Technology, 43, 17-27. http://dx.doi.org/10.1111/j.14678535.2010.01147.x

Ro, H. K., \& Loya, K. I. (2015). The effect of gender and race intersectionality on student learning outcomes in engineering. The Review of Higher Education, 38, 359-396. http://dx.doi.org/10.1353/rhe.2015.0014

Siemens, G. (2012). Learning analytics: Envisioning a research discipline and a domain of practice. Proceedings of the 2nd International Conference on Learning Analytics and Knowledge (LAK '12), 29 April-2 May 2012, Vancouver, BC, Canada (pp. 4-8). New York: ACM. http://dx.doi.org/10.1145/2330601.2330605 
Smith, G. G., Sorensen, C., Gump, A., Heindel, A. J., Caris, M., \& Martinez, C. D. (2011). Overcoming student resistance to group work: Online versus face-to-face. The Internet and Higher Education, 14, 121-128. http://dx.doi.org/10.1016/j.iheduc.2010.09.005

Snyder, V., Hackett, R. K., Stewart, M., \& Smith, D. (2003). Predicting academic performance and retention of private university freshmen in need of developmental education. Research and Teaching in Developmental Education, 19(2), $17-28$.

Stinebrickner, R., \& Stinebrickner, T. (2014). Academic performance and college dropout: Using longitudinal expectations data to estimate a learning model. Journal of Labor Economics, 32, 601-644. http://dx.doi.org/ 10.1086/675308

Tempelaar, D. T., Rienties, B., \& Giesbers, B. (2015). In search for the most informative data for feedback generation: Learning Analytics in a data-rich context. Computers in Human Behavior, 47, 157-167. https://dx.doi.org/10.1016/j.chb.2014.05.038

Tinto, V. (1975). Dropout from higher education: A theoretical synthesis of recent research. Review of Educational Research, 45, 89-125. http://dx.doi.org/10.3102/00346543045001089

Zacharis, N. Z. (2015). A multivariate approach to predicting student outcomes in web-enabled blended learning courses. The Internet and Higher Education, 27, 44-53. http://dx.doi.org/ 10.1016/j.iheduc.2015.05.002 
Appendix A.

Table 2. Summary of Statistical Analyses used in this Study

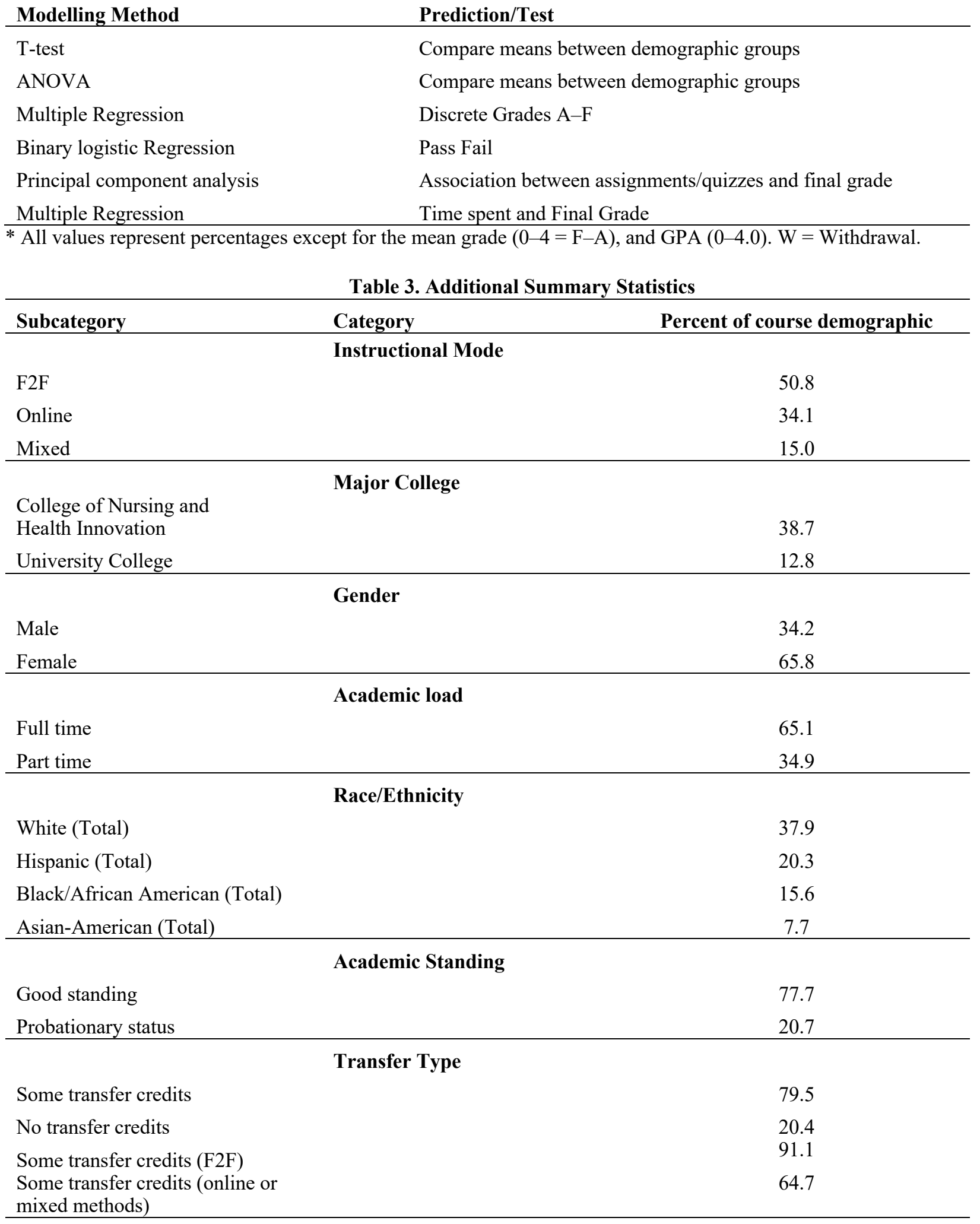


Total course credit hours

Average credit hours (all sections)

8.5

\section{Pell Status}

Eligible

42.6

Not eligible

26.6

Did not apply for FAFSA

30.9

\section{GPA}

Mean all sections

Mean F2F

Mean online

2.59

Mean mixed mode

2.54

\section{Prior College Mathematics}

Yes 36

No

64 